\title{
ADAPTACIONES CURRICULARES EN NIÑOS CON DISCAPACIDAD INTELECTUAL ASOCIADA A TRASTORNO ESPECTRO AUTISTA
}

\author{
AUTORES: Nilda Aracely Gómez-Macías ${ }^{1}$ \\ Kerly Aracely Zurita-Montero ${ }^{1}$ \\ Sandra Ximena Barberán-Zambrano ${ }^{1}$ \\ Gretty Alexandra Cabrera-Moreira ${ }^{1}$ \\ Julexy Alejandra Zambrano-Moreira ${ }^{1}$ \\ Ximena Lilibeth Cagua-Cedeño ${ }^{1}$ \\ Lilian Pilar Loor-Llanos ${ }^{1}$ \\ Kerlis Mercedes Moreira-Moreira ${ }^{1}$ \\ José Luis Barberán Díaz ${ }^{1}$ \\ Mildred Gissella Salazar-Ostaiza ${ }^{1}$ \\ Rocío Katiuska Santos-Zambrano ${ }^{1}$ \\ Concepción Elizabeth Marcillo-García ${ }^{2}$
}

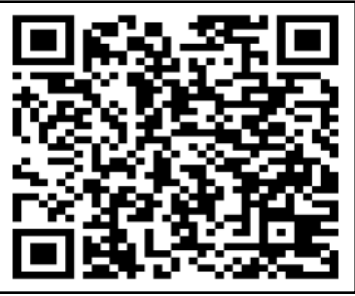

\section{DIRECCIÓN PARA CORRESPONDENCIA: (nilda.gomez@pg.uleam.edu.ec)}

Fecha de recepción: 22/10/2021

Fecha de aceptación: 28/12/2021

\section{RESUMEN}

El artículo aborda la problemática relacionada con las necesidades educativas especiales, tiene como objetivo compartir la experiencia desarrollada con niños que poseen discapacidad intelectual asociada a Trastorno Espectro Autista TEA; en el documento se explica el caso investigado en una estudiante de la provincia de Santo Domingo de los Tsáchilas - Ecuador, se muestran las orientaciones recibidas para trabajar este caso específico. La metodología que se utilizó para realizar la presente indagación fue deductiva-inductiva ya que permitió tener un mejor enfoque de la investigación, fue de gran utilidad para obtener información, permitiendo así la recolección de datos reales que se reflejan en este artículo, también se utilizó el método analítico-sintético para analizar los diferentes hechos y fenómenos relacionados con la

\footnotetext{
1 Posgradistas, Maestría en Ciencia de la Educación Básica, Extensión El Carmen. Universidad Laica Eloy Alfaro de Manabí, Ecuador. E-mail: nilda.gomez@pg.uleam.edu.ec, gretty.cabrera@pg.uleam.edu.ec, julexy.zambrano@pg.uleam.edu.ec, ximena.cagua@pg.uleam.edu.ec, lilian.loor@pg.uleam.edu.ec, kerlis.moreira@pg.uleam.edu.ec, joseluisbarberandiaz@gmail.com, mildred.salazar@pg.uleam.edu.ec, rocio.santos@pg.uleam.edu.ec.

2 Docente de Posgrado, Maestría en Ciencia de la Educación Básica, Extensión El Carmen. Universidad Laica Eloy Alfaro de Manabí. Docente Titular Universidad Estatal del Sur de Manabí, Ecuador. E-mail:concepcion.marcillo@unesum.edu.ec
} 
José L. Barberán Díaz; Sandra X. Barberán-Zambrano; Ximena Lilibeth Cagua-Cedeño; Gretty A. Cabrera-Moreira

problemática, la técnica de la observación fue utilizada para el registro de la evolución en el caso estudiado. El instrumento utilizado como parte de la intervención en esta investigación fueron las adaptaciones curriculares, en las que se describen las actividades a desarrollar según las recomendaciones emitidas por las áreas competentes como son la UDAI y DECE. Como resultado de la intervención, se ha logrado una mejor interacción con el entorno y adelantos en el desarrollo cognitivo y social de la estudiante.

PALABRAS CLAVE: Trastorno Espectro Autista, Discapacidad intelectual, adaptación curricular, necesidades educativas especiales, inclusión educativa.

\title{
CURRICULAR ADAPTATIONS IN CHILDREN WITH INTELLECTUAL DISABILITY ASSOCIATED WITH AUTISM SPECTRUM DISORDER
}

\begin{abstract}
The present research paper approaches teaching children with special educational needs. Its main objective is to share the experience developed with children who have intellectual disabilities associated with Autism spectrum disorder (ASD). The article explains the case of a student from the province of Santo Domingo of the Tsáchilas - Ecuador. It also provides the guidelines received to work on this specific case. The method used to carry out this investigation was the deductive-inductive, which allowed having a better approach to the investigation. It was very useful in order to get information, since it allowed the collection of real data that is reflected in this article. Furthermore, the analytical-synthetic method was used to analyze the different facts and phenomena related to the case. The observation technique helped to record the evolution in this paper. The curricular adaptations were the instruments used as part of the intervention in this research. These instruments present the activities to be developed according to the recommendations issued by the competent areas such as the UDAI and DECE. As a result of this process, the student has shown better interaction with the environment and advances in the cognitive and social development.
\end{abstract}

KEYWORDS: Autism Spectrum Disorder, Intellectual disability, curricular adaptation, special educational needs, inclusive education.

\section{INTRODUCCIÓN}

A nivel mundial existen niños que poseen diferentes trastornos mentales asociados a diversas discapacidades; de ahí la importancia de apoyar cada programa que ayude a orientar a las familias y la comunidad sobre las atenciones que se les debe brindar a este grupo de personas, valorando a los que tienen diferentes capacidades y que no poseen oportunidades para desarrollar sus habilidades en su entorno; sin embargo, eso no impide que ellos puedan compartir momentos inolvidables en su vida diaria junto a personas que le extienden la mano en una sociedad que avanza día a día.

108 UNESUM-Ciencias. Publicación cuatrimestral. Vol. 6, Año 2022, No. 1 (Enero - Abril) 
En este marco, Peredo, (2016) afirma que:

(...) cerca de 785 millones de personas $(15,6 \%)$ viven con algún tipo de discapacidad.Según la Encuesta Mundial de Salud conducida por la Organización Mundial de la Salud y el Banco Mundial en 2011, de las cuales alrededor de un 65\% se encuentranen los países en desarrollo y, aproximadamente, un $10 \%$ en Latinoamérica y el Caribe. La Encuesta señala que, del total estimado de personas con discapacidad, 110 millones (2,2\%) tienen dificultades muy significativas de funcionamiento. (párr.1).

De acuerdo con lo mencionado por Peredo (2016), se puede evidenciar que existen porcentajes altos a nivel mundial de personas que tienen diferentes tipos de discapacidades la cuales afectan al desarrollo de sus habilidades en el entorno.

Por otra parte, el Proyecto sobre la Carga Mundial de Morbilidad arrojó cifras algo más elevadas, ya que estimó una cifra próxima a 975 millones $(19,4 \%)$ de personas con discapacidad en el mundo, de las cuelas 190 millones $(3,8 \%)$ presentan una discapacidad grave. Asimismo, este proyecto evaluó las discapacidades infantiles (0-14 años) habiendo estimado que 95 millones $(5,1 \%)$ las presentan, de los cuales 13 millones $(0,7 \%)$ presentan discapacidad grave. (párr.2).

La OMS en conjunto con otros organismos se han preocupado por realizar investigaciones que permiten tener una perspectiva global sobre las discapacidades, tomando en cuenta a nivel mundial los casos que se han suscitado y que son de relevancia para investigar. En este sentido, el Ministerio de Salud Pública de Ecuador con el apoyo del CONADIS, MIES, IESS y Ministerio de Educación se han preocupado por llegar a las diferentes familias a través de mensajes, conferencias, medicina, atención prioritaria, rehabilitaciones, Unidad Distrital de Apoyo a la Inclusión (UDAI), entre otros, con el personal idóneo a realizar su trabajo en bien de la comunidad.

Según el Ministerio de Educación (2016), “La Constitución de la República del Ecuador Art. 47, Código de la niñez y de la adolescenciaen el Art. 6; la Ley Orgánica de Educación Intercultural, (2015) LOEI en el Art. 2, literal e; Art. 3, 26, 27, 28, 29, 32, entre otros, garantizan la educación para todos tomando en cuenta a toda la población, que puede ser considerada como población estándar y aquella que requiere de una educación inclusiva, ya que se les considera como personas con Necesidades Educativas Especiales (NEE)".

Se entiende por NEE, al conjunto de medidas pedagógicas que se ponen en marcha para compensar las dificultades que presenta un estudiante para acceder al currículo que le corresponde por edad. En este sentido las adaptaciones son necesarias e indispensables, parapoder garantizar en la educación el acceso a todos y que se puedan desarrollar en un ambienteseguro, que les genere aprendizajes útiles para su diario vivir" (Cedeño 2019, p.9).

Los estudiantes con necesidades educativas especiales poseen características que los hacen diferentes del resto de educandos por lo que resulta difícil homogeneizarlos y darles un trato generalizado dentro de un grupo de trabajo, sin embargo esta circunstancia no puede determinar que se los trate como alumnos deficientes sino más bien han de ser vistos como estudiantes con 
José L. Barberán Díaz; Sandra X. Barberán-Zambrano; Ximena Lilibeth Cagua-Cedeño; Gretty A. Cabrera-Moreira

capacidades diferentes que pueden ser aprovechadas por el docente como una oportunidad para enriquecer sus clases con estrategias que mejoren el aprendizaje de todo el grupo y el crecimiento de todos los estudiantes.

En la actualidad el sistema educativo ha desarrollado varias políticas públicas que hacen referencia a la inclusión donde se mantiene en el sistema regular educativo a las personas que presentan necesidades educativas especiales asociadas o no a una discapacidad, esto enfocado al desarrollo integral de la ciudadanía en general. Por lo que la planificación para las adaptaciones curriculares debe cobijarse en la flexibilidad del currículo, asociando la modificación metodológica y evaluativa de los contenidos a los informes psicopedagógicos entregados al personal docente.

Las adaptaciones curriculares son instrumentos indispensables en los que se modifican uno o varios elementos del currículo, para lograr los objetivos educativos en estudiantes con necesidades educativas especiales, promoviendo una educación con mejores prácticas pedagógicas (Begoña, 2002).

Complementariamente, Real \& Marcillo (2021) consideran que "las adaptaciones curriculares presentarán características individualizadas de acuerdo a las necesidades de aprendizaje del educando e irán cambiando progresivamente según sea el avance académico del estudiante en el proceso formativo".

En el marco de la educación inclusiva, el Ministerio de Educación de Ecuador ha proporcionado a los docentes, una Guía de trabajo sobre Adaptaciones Curriculares para la educación especial $e$ inclusiva, documento que aporta con conceptos y procesos para la planificación de las adaptaciones curriculares y su posterior aplicación.

Este proceso implica cambios y modificaciones en contenidos, métodos, estructuras y estrategias que se utilizan en la escuela regular, en busca de un enfoque común, con el objetivo de aportar respuestas pertinentes a toda la gama de necesidades educativas, dando lugar a dificultades en áreas principales como la comunicación e interacción social y la flexibilidad del pensamiento y de la conducta.

Teniendo en cuenta que existen varias discapacidades la presente investigación se enfoca en la discapacidad intelectual, en específico del Espectro Autista (TEA) que se caracteriza por limitaciones significativas, tanto en el funcionamiento intelectual, como en la conducta adaptativa, originándose antes de los 18 años.

El TEA hace referencia a un conjunto de alteraciones del neurodesarrollo que se caracterizan, principalmente, por deficiencias en la interacción y comunicación social, así como por intereses y conductas restringidas y repetitivas. (Aliaga, et. Al., 2020)

En esta línea, la integración escolar no es un fin en sí misma, sino un medio que permite formar parte de una estrategia más amplia, cuya meta sea alcanzar una educación de calidad, integral e integradora para todos y todas.

110 UNESUM-Ciencias. Publicación cuatrimestral. Vol. 6, Año 2022, No. 1 (Enero - Abril) 
Ante lo expuesto, la realidad que viven los niños con TEA debe ser considerada de manera muy personal, aunque los docentes de las instituciones educativas no cuenten con la formación y el conocimiento que esto demanda, ejercen su rol dando lo mejor de sí, para ayudar a las familias. Particularmente, Santo Domingo de los Tsáchilas es una provincia que a través de losorganismos competentes trabaja constantemente en armonía con el Gobierno Nacional. De ahí que el objetivo de esta investigación se centra en compartir la experiencia de intervención mediante adaptaciones curriculares en niños con DiscapacidadIntelectual asociada al TEA.

\section{DESARROLLO}

La metodología que se utilizó para realizar la presente indagación es deductiva-inductiva yaque permite tener un mejor enfoque de la investigación. Además, durante el desarrollo del presente análisis científico fue necesario recurrir al apoyo de varios instrumentos, técnicas y revisiones bibliográficas, revisión documental, fuentes de consulta como son: bibliotecas virtuales, libros electrónicos, artículos, revistas y guías de adaptación curricular de autores relevantes que han sido de gran utilidad para obtener información eficiente y eficaz, permitiendo así la recolección de datos reales que se reflejan en este artículo.

El método Analítico-sintético se utilizó para analizar los diferentes hechos y fenómenos involucrados en la problemática. El método Inductivo-Deductivo permitió realizar deducciones para lograr sustentar la experiencia vivida y aportar a la solución; además se necesitó de la recolección de información ubicada en distintas bases de datos para fundamentar teóricamente la presente investigación. Así mismo, se realizó una investigación documental que permitió la revisión de archivos y documentos propios del caso, de igual manera se contó con la observación científica.

\section{RESULTADOS Y DISCUSIÓN}

\section{Descripción del Caso}

Estudiante de sexo femenino fue remitida al Departamento de Consejería Estudiantil (DECE) por parte de la docente tutora cuando asistía al primer año de Educación Básica, debido a que la docente de turno observó algunos comportamientos y un desarrollo un tanto inmaduro en su desenvolvimiento considerando la edad que tenía en aquel momento. Por la sospecha de que la estudiante podría presentar dificultades de aprendizaje o algo relacionado a aquello, realizó los procesos pertinentes paraque fuera evaluada por los profesionales correspondientes.

El DECE realizó los procesos pertinentes que exigen las leyes ecuatorianas con el consentimiento de los padres de la estudiante, por lo que tras las evaluaciones realizadas se pudo determinar que la estudiante poseía Trastorno del Espectro Autista (TEA). Se recomendó aplicar adaptaciones curriculares apropiadas a las necesidades educativas presentes en la niña, ya que este tipo de 
José L. Barberán Díaz; Sandra X. Barberán-Zambrano; Ximena Lilibeth Cagua-Cedeño; Gretty A. Cabrera-Moreira

trastorno tiene ciertas características a las que se debe poner atención y énfasis para ayudar a mejorar los procesos de escolaridad realizando intervenciones acertadas y eficientes.

Al momento de la investigación la estudiante cursa el séptimo año de básica y continúa aplicándosele las debidas adaptaciones, siguiendo las recomendaciones sugeridas por los diferentes equipos de especialistas como neurólogo, sicólogo clínico, y las directrices entregadas por la Unidad Distrital de Apoyo a la Inclusión (UDAI) para que el proceso de inclusión educativa se cumpla y que todos los conocimientos que necesita la estudiante para desenvolverse en la vida cotidiana sean las más adecuadas.

Luego de realizar las valoraciones pertinentes se determinó en el informe lo siguiente:

\section{Diagnóstico}

El DECE como departamento encargado de realizar los procesos y, tomando en cuenta las rutas y protocolos debidos, obtuvo el diagnóstico médico que fue realizado por profesionales del Ministerio de Salud de Ecuador; en este diagnóstico se detalla lo que pudieron evidenciaren su momento y sobre los aspectos valorados que se deben trabajar.

Dentro de la valoración que realizó la Sicóloga Pedagoga, aplicando el test de inteligencia nivel mental- "Pressey". Una vez aplicado el test y aplicando la escala psicométrica de coeficiente intelectual Pressey $\quad \mathrm{CI}=\frac{E M X 100}{E C}$ se determina que la estudiante no retiene información, y que el coeficiente intelectual se encuentra en el rango 20-49 inferior (E.M.2 a7 años).

Con base en estos resultados se hizo constar que se encuentra:

- $\quad$ FT1 retraso mental moderado

- Trastorno de lenguaje

- G40 epilepsia

- F84 autismo

Se recomienda:

- Terapia ocupacional

- Terapia de lenguaje

- Fisioterapia motricidad fina

- Hidroterapia

- Precaución con las caídas por epilepsia. Vigilancia permanente con un familiar

- Informe de salud pública atendida por el neurólogo.

- Tiene discapacidad intelectual con un porcentaje del $63 \%$ con un nivel grave

- Diagnóstico retraso mental leve deterioro del comportamiento de grado no

- Epilepsia y síndromes epilépticos sintomáticos relacionados $\mathrm{C}$

- El periodo de adquisición durante el parto- asfixia.

112 UNESUM-Ciencias. Publicación cuatrimestral. Vol. 6, Año 2022, No. 1 (Enero - Abril) 
Después de haber realizado el diagnóstico y haberse comprobado que la estudiante posee, retraso mental moderado, Trastorno de lenguaje, epilepsia, autismo discapacidad intelectual, se procede a trabajar siguiendo las recomendaciones de la UDAI como departamento encargado de elaborar las recomendaciones para el trabajo en el aula tomando en cuenta el diagnóstico médico, para esto se aplica la adaptación curricular en la planificación innovando métodos de la observación y técnicas utilizadas fueron: rasgado, entorchado, trozado, arrugado, embolillado, dactilopintura, entre otros. De acorde con la edad que infiere la estudiante.

Por presentarse una necesidad educativa permanente asociada a una discapacidad, la UDAI emite un informe con los detalles a tomar en cuenta para la aplicación de las adaptaciones curriculares de manera que beneficien al desarrollo de capacidades y habilidades en la estudiante para su diario vivir.

Entre estas especificaciones se mencionan las siguientes:

- Se debe realizar adaptaciones curriculares de grado 3 no significativas, ya que este tipo de adaptación permiten al estudiante con NEE aprender de una manera significativa, facilitando la comprensión de los contenidos o aprendizaje al estudiante, haciendo que el docente realice planificaciones dinámicas e interactivas, adaptando estrategias y metodologías buscando consolidar los conocimientos básicos requeridos para un mejor desenvolvimiento académico del mismo.

- Trabajar de acuerdo con los estándares de calidad educativa enmarcados en la necesidad de la estudiante y que sirva de herramienta principal para alcanzar los logros académicos y a su vez que se relacione con el nivel de conocimientos.

- Realizar adaptaciones curriculares con base en los estándares de aprendizaje que son las descripciones de los logros del conocimiento que constituyen referentes comunes que los estudiantes deben alcanzar a lo largo de la trayectoria escolar de acuerdo con el nivel en que se encuentra la estudiante y potenciar sus habilidades.

- Fortalecer el desarrollo cognitivo.

- Potenciar su autonomía.

- Mejorar sus habilidades y expresión social, expresión verbal y motricidad.

- Realizar el reconocimiento corporal.

- Fortalecer el área de comunicación (vocabulario, comprensión y expresión oral, identificación de colores primarios y secundarios, identificación de figuras geométricas, nociones espaciales, y área de autonomía).

- Fortalecer el área de motricidad fina, gruesa, lectura y escritura, y patrones.

\section{Aplicación}

Con las sugerencias realizadas por la UDAI, se ha trabajado con la estudiante desde el primer año de educación básica aplicando las modificaciones correspondientes, de manera que, los contenidos transmitidos sean los más idóneos a sus capacidades de comprensión y ejecución. 
José L. Barberán Díaz; Sandra X. Barberán-Zambrano; Ximena Lilibeth Cagua-Cedeño; Gretty A. Cabrera-Moreira

Actualmente, como ya se mencionó, la estudiante cursa el séptimo año de educación básica, y a pesar de la situación que se atraviesa a nivel global debido a la crisis sanitaria por el virus del Covid-19, la aplicación de las adaptaciones curriculares se siguen dando sin problema alguno como exige la LOEI, pero con la variación de que se desarrollan a través de la virtualidad y con el apoyo de su representante, debido a que este es el modelo adoptado por el Estado y el Ministerio de Educación ecuatoriano para garantizar la continuidad de los estudios a través de las plataformas digitales.

Entre las metodologías y técnicas aplicadas con base en las sugerencias que realiza el documento, la maestra ha desarrollado, de manera general las siguientes acciones:

- Interacción estudiante - docente mediante el uso de las plataformas digitales para reforzar temas de importancia e interés para la estudiante.

- Trabajos con tarjetas de imágenes para mejorar su función de memorización.

- Utilización de materiales reciclables para el desarrollo de actividades pedagógicas.

- Emplear estilos de aprendizaje en cuanto a las habilidades y fortalezas que posee la niña.

- Aplicar estándares de calidad educativas enmarcados en la necesidad y que sirvan de herramienta principal para alcanzar los logros académicos de las cuatro áreas básicas relacionándolas con el nivel de conocimiento.

- Adaptar los contenidos al nivel educativo de la estudiante.

A nivel específico y para desarrollar cada una de las habilidades que necesita la estudiante para su desenvolvimiento se han realizado las siguientes actividades:

\section{Fortalecer el desarrollo cognitivo}

- Presentación de cartillas con imágenes, vocales, animales, colores, números,formas, tamaño, para su reconocimiento.

- Videos interactivos con cuentos, información básica,

- Audios educativos.

- Memorización de canciones.

- Identificación de palabras, sonidos, sensaciones.

- Juegos y dinámicas que incluyan el aprendizaje de reglas.

- Lectura con pictogramas

\section{Potenciar su autonomía}

- $\quad$ Realizar actividades dentro del hogar acordes a su capacidad (arreglar cama, lavarsus utensilios, vestirse sola, entre otros)

- $\quad$ Prender y apagar su cámara en la computadora mientras está en clases.

- $\quad$ Establecer rutinas.

- $\quad$ Establecer límites de las cosas que desea.

- $\quad$ Pedir que organice algún juego de su agrado.

Mejorar sus habilidades sociales

Practicar su deporte favorito en casa con su familia. Potenciar hábitos de saludos.

114 UNESUM-Ciencias. Publicación cuatrimestral. Vol. 6, Año 2022, No. 1 (Enero - Abril) 
- $\quad$ Usar el lenguaje facial apropiadamente.

- Participar de música terapias en el hogar.

Realizar reconocimiento corporal

- $\quad$ Practicar el juego del espejo.

- Juego de la estatua.

- Cantar canciones de las partes del cuerpo

- Observar videos interactivos de las partes del cuerpo

Fortalecer el área de comunicación

- Identificar mediante cartillas con saludos, expresiones, gestos, sentimiento o emociones, para aplicarlas en la cotidianidad.

- $\quad$ Practicar saludos de acuerdo con el horario del día.

- Contar cuentos

- $\quad$ Interactuar con canciones, videos y prácticas con sus pares.

Fortalecer la motricidad fina, gruesa

- Cortar papeles en trozos pequeños, los cuales pueden utilizar para llenar una botella o bolsa.

- $\quad$ Envolver objetos pequeños en papel.

- $\quad$ Abrochar y desabrochar botones de sus prendas.

- $\quad$ Enroscar tapas de distintos envases.

- Cortar siguiendo una línea recta, luego inclinada u oblicua.

- $\quad$ Hacer formas con plastilina para luego cortarlas en trozos con la tijera.

- $\quad$ Atar cordones.

- $\quad$ Subir y bajar gradas

- Caminar encima de una cuerda

- Patear una pelota

- $\quad$ Recoger juguetes u objetos y colocarlos en una cesta o recipiente.

- Lanzar pelotas a un recipiente

- Danzar

- $\quad$ Clasificar granos que se encuentren revueltos, separarlos y ubicarlos en diferentes recipientes

- $\quad$ Colorear imágenes.

- $\quad$ Pintar usando pincel y témperas en hojas, tablas y objetos.

Todas las actividades que se describen están basadas en el último informe realizado por la UDAI que se guía mediante el informe médico realizado en enero del 2021.

\section{Planificación de la adaptación curricular}

Se presenta un ejemplo de adaptación curricular aplicado en este caso, en ella se reflejan los métodos y técnicas aplicadas en clase a la estudiante. La planificación es flexible, se adapta a las necesidades de la estudiante tomando en consideración el grado de dificultad que presenta el educando. 
José L. Barberán Díaz; Sandra X. Barberán-Zambrano; Ximena Lilibeth Cagua-Cedeño; Gretty A. Cabrera-Moreira

Tabla 1: Planificación de Adaptación Curricular

\begin{tabular}{|c|c|c|c|c|c|c|}
\hline \multicolumn{7}{|c|}{ Planificación de Adaptación Curricular } \\
\hline \multicolumn{2}{|c|}{$\begin{array}{l}\text { EXPERIENCIADE } \\
\text { APRENDIZAJE: }\end{array}$} & \multicolumn{5}{|c|}{ Cuido mi cuerpo / Dientes sanos } \\
\hline \multicolumn{2}{|c|}{$\begin{array}{l}\text { NIVEL } \\
\text { EDUCATIVO: }\end{array}$} & $\begin{array}{l}\text { Básica } \\
\text { media }\end{array}$ & $N^{\circ}$ DE NIÑOS/AS & PARALELO: A & $\begin{array}{l}\text { QUIMESTRE: } \\
\text { Primero }\end{array}$ & \\
\hline \multicolumn{2}{|c|}{$\begin{array}{l}\text { TIEMPO } \\
\text { ESTIMADO: }\end{array}$} & \multicolumn{2}{|c|}{1 semana } & FECHA: & \multicolumn{2}{|l|}{2021} \\
\hline \multicolumn{2}{|c|}{$\begin{array}{l}\text { DESCRIPCIÓN } \\
\text { GENERAL DE LA } \\
\text { EXPERIENCIA: }\end{array}$} & \multicolumn{5}{|c|}{$\begin{array}{l}\text { El aseo personal es un hábito que se debe fomentar en los niños y niñas desde tempranas } \\
\text { edades. La salud dental se puede lograr a través de actividades, juegos y canciones que, } \\
\text { a más de construir hábitos dentales saludables, desarrollanhabilidades y destrezas } \\
\text { propias de estas edades. }\end{array}$} \\
\hline ÁMBITOS & \multicolumn{2}{|c|}{ DESTREZAS } & \multicolumn{2}{|c|}{ ACTIVIDADES } & $\begin{array}{c}\text { INDICADORES } \\
\text { PARA } \\
\text { EVALUAR }\end{array}$ & $\begin{array}{l}\text { INDICADORES PARA } \\
\text { EVALUAR }\end{array}$ \\
\hline $\begin{array}{l}\text { dentidad y } \\
\text { Autonomía }\end{array}$ & \multicolumn{2}{|c|}{$\begin{array}{l}\text { CS.1.1.7. Practicar } \\
\text { hábitos de } \\
\text { alimentación, } \\
\text { higiene y cuidado } \\
\text { personal con } \\
\text { autonomía. }\end{array}$} & \multicolumn{2}{|c|}{$\begin{array}{l}\text { Lunes } \\
\checkmark \text { Observar el cuento de motivación } \\
\text { "Paco el cocodrilo que noquería } \\
\text { cepillarse los dientes" } \\
\text { https://www.youtube.com/watch?v= } \\
\underline{15 \text { tsGQ3htUs\&t=84s }} \\
\checkmark \text { Dialogar acerca del cuento } \\
\checkmark \text { Identificar y cuáles son los útiles de } \\
\text { aseo bucal(imágenes) } \\
\checkmark \text { Presentar su cepillo de dientes y su } \\
\text { pasta dental, ayúdela a que escoja } \\
\text { entre los cepillos acordes asu edad, así } \\
\text { fomentará la toma de decisiones } \\
\checkmark \text { Dibujar los materiales de aseo }\end{array}$} & $\begin{array}{l}\text { Uso de las TIC } \\
\text { Pasta dental } \\
\text { Cepillo } \\
\text { Lápiz } \\
\text { Hoja }\end{array}$ & $\begin{array}{l}\text { I.CS.1.2.1. Práctica } \\
\text { con autonomía y } \\
\text { responsabilidad } \\
\text { actividades y tareas } \\
\text { cotidianas,como } \\
\text { hábitos de } \\
\text { alimentación, higiene } \\
\text { y cuidado personal. } \\
\text { (J.3., I.4.) }\end{array}$ \\
\hline $\begin{array}{l}\text { Relación } \\
\text { ógico } \\
\text { matemático }\end{array}$ & $\begin{array}{l}\text { M.1.4 } \\
\text { stingu } \\
\text { ubica } \\
\text { objet } \\
\text { entor } \\
\text { las } \\
\text { arriba } \\
\text { delan } \\
\text { encim } \\
\text {. }\end{array}$ & $\begin{array}{l}\text { Di } \\
\text { la } \\
\text { de } \\
\text { del } \\
\text { según } \\
\text { lociones } \\
\text { abajo, } \\
\text { /atrás y } \\
\text { /debajo }\end{array}$ & $\begin{array}{l}\text { Martes } \\
\text { Observar el vide } \\
\text { los } \\
\text { https://youtu.be }\end{array}$ & $\begin{array}{l}\text { sí es como se lavan } \\
\text { dientes" } \\
\text { zoS31BM }\end{array}$ & $\begin{array}{l}\text { Pasta } \\
\text { dental } \\
\text { Cepillo. } \\
\text { Goma } \\
\text { Periódico } \\
\text { TIC, } \\
\text { Etc. }\end{array}$ & $\begin{array}{l}\text { I.M.1.1.1. Compara } \\
\text { y distingue objetos } \\
\text { según su color, } \\
\text { tamaño, longitud, } \\
\text { textura y forma en } \\
\text { situaciones }\end{array}$ \\
\hline
\end{tabular}

116 UNESUM-Ciencias. Publicación cuatrimestral. Vol. 6, Año 2022, No. 1 (Enero - Abril) 


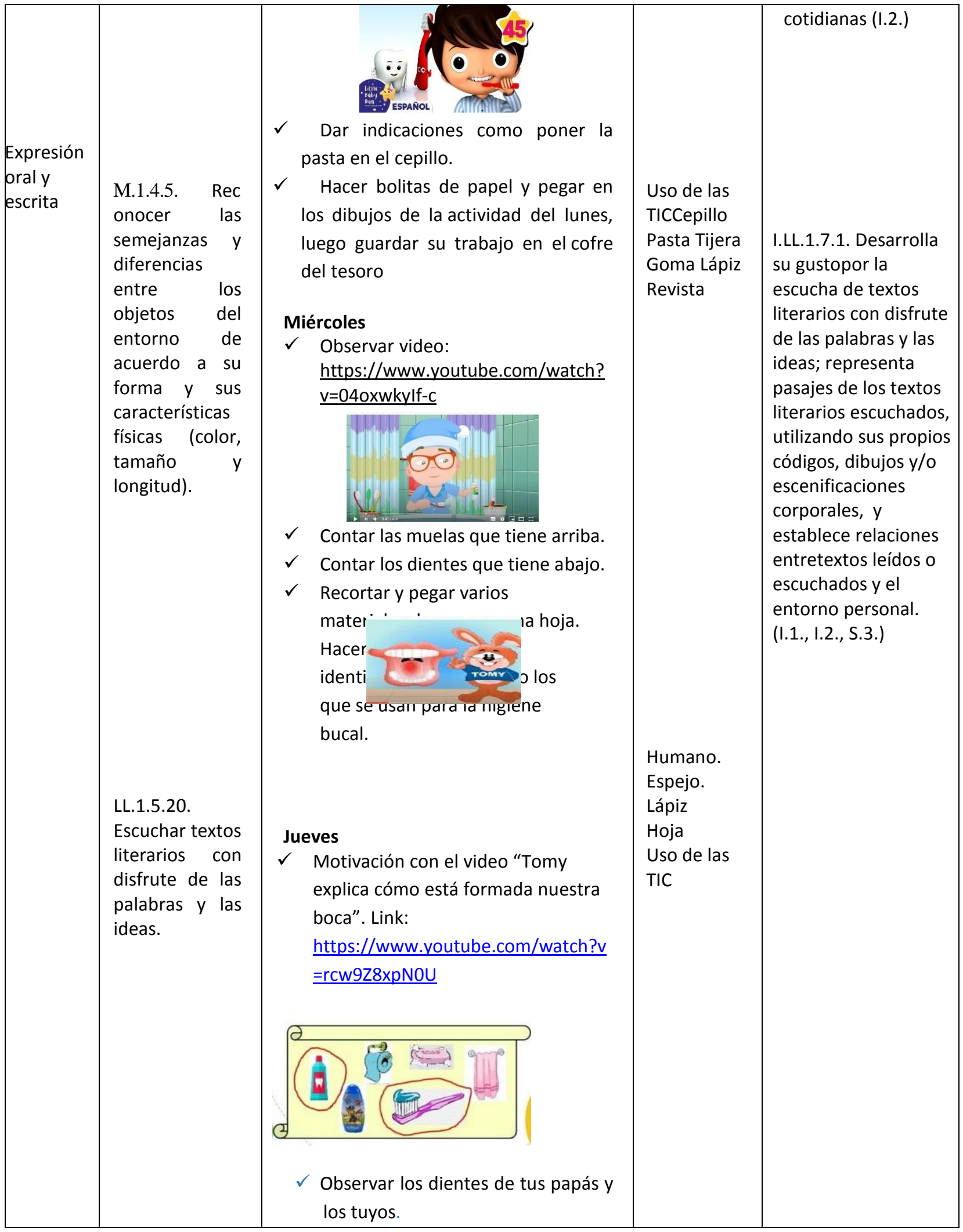

○ Universidad Estatal del Sur de Manabí. Jipijapa, Ecuador. 


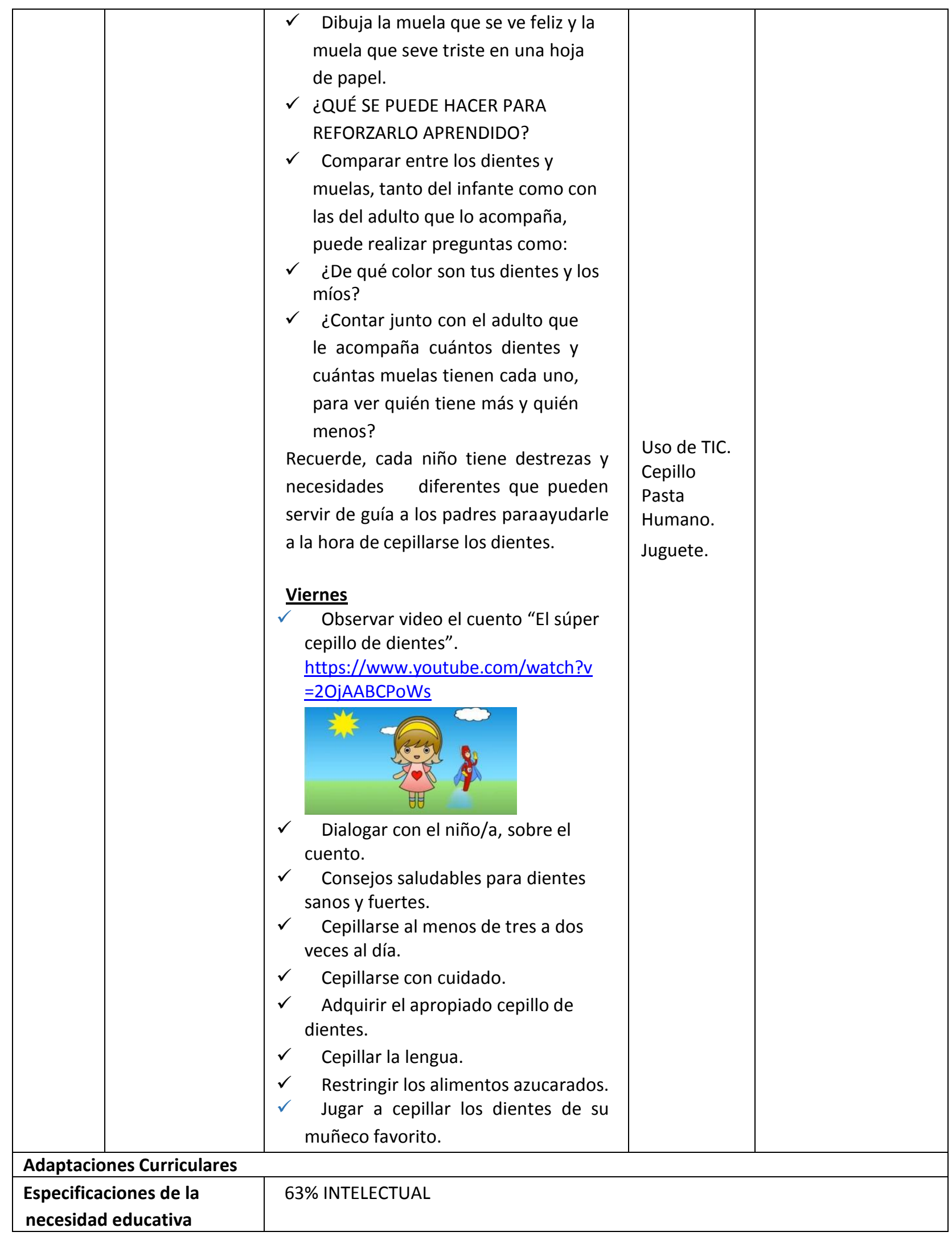

118 UNESUM-Ciencias. Publicación cuatrimestral. Vol. 6, Año 2022, No. 1 (Enero - Abril) 
\begin{tabular}{ll|l} 
Adaptaciones Curriculares & L.M.G. Z
\end{tabular}

Individuales

\section{Resultados de la intervención}

Los resultados obtenidos a través de la aplicación de las diferentes actividades en las adaptaciones curriculares son los siguientes:

Fortalecer el desarrollo cognitivo

- $\quad$ Reconoce y diferencia imágenes (animales, frutas, objetos)

- $\quad$ Reconoce y diferencia sabores (dulce, salado, acido)

- $\quad$ Identifica y reconoce las vocales.

- $\quad$ Repite canciones cortas y de su agrado.

\section{Potenciar su autonomía}

- Arregla su habitación.

- $\quad$ Lava sus utensilios.

- $\quad$ Se viste y se peina sola.

- $\quad$ Activa, desactiva cámara y micrófono mientras está en la actividad online.

- $\quad$ Participa en juego de cartas.

- $\quad$ Reconoce los colores primarios a través de imágenes.

Mejorar sus habilidades sociales

- Juega con el balón involucrando a sus familiares.

- $\quad$ Practica a diario los saludos según los horarios que se encuentre.

- $\quad$ Realiza movimiento básico de baile.

Realizar reconocimiento corporal

- $\quad$ Reconoce e identifica las partes de su cuerpo.

Fortalecer el área de comunicación

- $\quad$ Expresa e identifica las diferentes emociones.

- $\quad$ Escucha cuentos e inventa historias.

Fortalecer la motricidad fina, gruesa.

- $\quad$ Recorta papeles con la ayuda en trozos pequeños, los cuales los utiliza para llenaruna botella o bolsa.

- $\quad$ Envuelve piedras pequeñas en papeles de varios colores.

- $\quad$ Abrocha y desabrocha botones de sus prendas.

- $\quad$ Enrosca tapas de distintos envases.

- $\quad$ Plasma formas con plastilina para luego cortarlas en trozos con la tijera.

- $\quad$ Ata sus cordones.

- $\quad$ Sube y baja gradas con ayuda.

- $\quad$ Camina encima de una cuerda con ayuda.

- $\quad$ Patea una pelota sin apoyo.

- $\quad$ Recoge juguetes u objetos y los coloca en una cesta o recipiente.

- $\quad$ Clasifica granos que se encuentren revueltos, los separa según su color.

- $\quad$ Colorea imágenes.

- $\quad$ Pinta usando pincel y témperas en hojas, tablas y objetos. 
José L. Barberán Díaz; Sandra X. Barberán-Zambrano; Ximena Lilibeth Cagua-Cedeño; Gretty A. Cabrera-Moreira

\section{CONCLUSIONES}

Las adaptaciones curriculares caracterizadas según el desarrollo cognitivo del estudiante con necesidades educativas especiales ayudan a mejorar sus habilidades, su capacidad intelectual y a desenvolverse de mejor manera dentro del entorno.

La ciencia ha realizado contribuciones sobre el tema que favorecen la comprensión de las diferentes necesidades educativas que puede presentar un estudiante. De otra parte, las políticas de estado, en el caso particular del Ministerio de Educación de Ecuador en la medida que proporciona normativas y diferentes materiales curriculares, dan soporte fundamental para ayudar y plantear soluciones en bien de las necesidades educativas en sus diferentes manifestaciones, en este caso del Trastorno Espectro Autistas.

Cada niño/a con discapacidad intelectual es capaz de aprender, desarrollarse y vivir una vida plena acorde a su necesidad con ayuda de las personas que forman parte de su entorno familiar, social y educativo.

\section{REFERENCIAS BIBLIOGRÁFICAS}

Aliaga, Lopez-Fernández, Torres-Chamorro y Vasquez-Florentino (2020). Teleasistencia psicológica para niños con Trastorno del Espectro Autista: definiciones, directrices y tendencias tecnológicas para el trabajo basado en evidencia. Instituto Psicopedagógico EOS Perú.

Argüello, M. (2013), Adaptaciones curriculares para la educación especial e inclusiva. Guía de Trabajo. Ministerio de Educación. Quito, Ecuador.

Begoña, G. (2002). Constructivismo y diseño de entornos virtuales de aprendizaje. Revista de Educación, 225.

CE (2015). Constitución del Ecuador, 21 de diciembre de 2015. Registro oficial 449 de 20 de octubre 2008.

LOEI (2021), Ley Orgánica de Educación Intercultural, Ley 0

Registro Oficial Suplemento 417 de 31-mar.-2011. Última modificación: 19-abr.-2021. Reformado

Real-Loor, C. \& Marcillo-García, C. (2021) Adaptaciones curriculares en entornos virtuales de aprendizaje. Revista Científica Dominio de las Ciencias. Vol 7, núm. 1, Especial febrero 2021, pp. 951-970

Peredo, R. (2016). Comprendiendo la discapacidad intelectual datos, criterios y reflexiones. Revista de Psicología No.15. La Paz, jun. 2016. Páginas 5-22.

120 UNESUM-Ciencias. Publicación cuatrimestral. Vol. 6, Año 2022, No. 1 (Enero - Abril) 